\title{
Evaluation of Salt, Microbial Transglutaminase and Calcium Alginate on Protein Solubility and Gel Characteristics of Porcine Myofibrillar Protein
}

\author{
Geun Pyo Hong and Koo Bok Chin* \\ Department of Animal Science and Biotechnology Research Institute, Chonnam National University, \\ Gwangju 500-757, Korea
}

\begin{abstract}
Response surface methodology was adopted to model and optimize the effects of microbial transglutaminase (TG) and calcium alginate (CA) systems of various ratios on the gelation characteristics of porcine myofibrillar protein (MP) at various salt levels. The CA system consisting of sodium alginate (SA), calcium carbonate (CC) and glucono- $\delta$-lactone (GdL) showed no remarkable changes in the salt-soluble fraction, and only minor effects on electrostatic interactions were observed. Increasing CA concentration caused acid-induced hydrophobic interactions in MPs, resulting in increased MP gel strength. The TG system, containing TG and sodium caseinate (SC), induced cold-set MP gelation by formation of covalent bonding. The main advantage of the combined system was a higher cooking yield when the MP gel was heated. These results indicated that $0.7 \%$ TG combined with $0.8 \%$ CA system can form a viscoelastic MP gel, regardless of salt levels.
\end{abstract}

Key words: Microbial transglutaminase, calcium alginate, myofibrillar protein, gel characteristics

\section{Introduction}

Protein gelation techniques are related to the physical and chemical properties of protein based gel type foods such as cheese, surimi and sausage (Boles and Shand, 1998; Park, 2000). In the last few decades, numerous procedures in protein gelation have been introduced, and some chemical ingredients, including microbial transglutaminase (TG), calcium alginate (CA) and fibrinogen/ thrombin (Boles and Shand, 1998), have been available to form a cold-set gel.

In most cases, TG was intensively investigated as a cold-set gelling system. The TG mediated meat binding or protein gelling mechanisms have been published (Folk, 1980; Ramírez-Suárez and Xiong, 2003; Chin et al., 2009a). Nielsen et al. (1995) investigated the effects of $F$ XIIIa, a TG from plasma, on cold-set meat binding and reported that the enzyme had the highest activity at $37^{\circ} \mathrm{C}$, while no or minor effects at refrigerated temperature. However, this endogenous TG is $\mathrm{Ca}^{2+}$-dependent for their activity, and therefore, microbial TG is easier to use in

*Corresponding author: Koo Bok Chin. Department of Animal Science and Biotechnology Research Institute, Chonnam National University, Gwangju 500-757, Korea Tel: 82-62-5302121, Fax: 82-62-530+2129, E-mail: kbchin@chonnam.ac.kr food processing (Park, 2000). Kuraish et al. (1997) postulated that TG system, which consisted of microbial TG and sodium caseinate (SC) as a substrate, could restructure the meat particles at refrigeration temperature without salt or cooking, whereas, most of research reported that TG activity on meat binding was salt-dependent (Ramírez et al., 2002; Kütemeyer et al., 2005; Chin et al., 2009a). These inconsistent results were probably dependent on processing conditions, the source of TG, type of substrates or sample materials as well as activity of TG itself (Nielsen et al., 1995; Kuraish et al., 1997; Ramírez et al., 2002; Chin et al., 2009b). According to our preliminary study (Hong and Chin, 2009), TG activation for cold-set MP gelation was highly correlated to salt and substrate (SC) concentrations, and TG combined with SC was suggested as a best MP gelling system (Kuraishi et al., 1997). In consequence, the efficacy of the TG system on cold-set MP gelation predominantly increased with increasing salt concentration, and the optimum ratio of TG and SC was 6:5 (Hong and Chin, 2009).

CA system, which is one of main cold-set gelling systems, consisted of sodium alginate (SA), calcium carbonate $(\mathrm{CC})$ as a $\mathrm{Ca}^{2+}$ source and glucono- $\delta$-lactone (GdL) as an acidulant. Although, calcium chloride was generally used as a basic calcium source in calcium alginate system, this system could not produce a uniform cold-set gel 
due to immediate formation of CA (Means and Schmidt, 1986). Despite of their non-toxic and highly functional properties, application of CA system on cold-set MP gelation was not used commercially. To manufacture low salt, cold-set meat products, CA is the best system, because it can form a thermally irreversible gel at no or low salt concentrations (Means and Schmidt, 1986, 1987; Boles and Shand, 1998; Hong and Chin, 2010b). However, increasing salt concentration decreased the CA gel formation (Hong and Chin, 2010b) because of competition between $\mathrm{Na}^{+}$and $\mathrm{Ca}^{2+}$ at the G-block binding sites in sodium alginate (Draget et al., 1991). Although, increasing GdL levels in CA system enabled the formation of a cold-set MP gel even with a higher salt concentration, GdL was detrimental in protein-water interactions, resulting in low final yield after thermal processing (Hong and Chin, 2010b). To eliminate GdL induced moisture loss of the MP gel, all systematic components i.e., SA, CC and $\mathrm{GdL}$, had to be optimized at various salt concentrations, and the results showed that optimum ratio of SA, CC and GdL levels was 1:0.3:1 (Hong and Chin, 2009).

Consequently, MP containing relatively no $(<0.1 \mathrm{M})$ or high salt $(>0.3 \mathrm{M})$ enabled the formation of a cold-set gel by addition of CA or TG systems, while these systems had no effects on MP gelation at approximately $0.2 \mathrm{M}$ salt concentration which was a typical salt content in actual meat products (Hong and Chin, 2009). Based on these results, a stable cold-set MP gel could be formed at salt concentrations between 0.1 and $0.4 \mathrm{M}$ by combining these two cold-set gelling systems. Therefore, this study aimed to find out the best combination of TG with CA system at various salt concentrations and to determine the changes in the interactions involved in MP gelation.

\section{Materials and Methods}

\section{Materials}

Porcine longissimus dorsi muscles (crossbreed of Landrace $\times$ Yorkshire $\times$ Duroc, 6 month old hogs), with $\mathrm{pH} 5.5$ 5.7 , were selected from three carcasses at $24 \mathrm{~h}$ post-mortem. The pork loin trimmed off all visible fat and connective tissue and cut into $1 \mathrm{~cm}$ cubes. The meat cubes were distributed into $200 \mathrm{~g}$ portions, vacuum-packed in a polyethylene pouch, and frozen at $-70^{\circ} \mathrm{C}$ prior to use. Microbial transglutaminase (TG, Activa-TI, 1\% TG with 99\% maltodextrin) was donated by Ajinomoto Food Ingredients (Chicago, IL, USA). Sodium alginate (SA) with $230 \mathrm{kDa}$ of molecular weight and 0.38 of $\mathrm{M} / \mathrm{G}$ ratio (ratio of mannuronic to galuronic acid) was purchased from
Junsei Chemical (Tokyo, Japan). All other chemicals were analytical grade.

\section{Extraction of Myofibrillar Protein (MP)}

Frozen meat was thawed at $4^{\circ} \mathrm{C}$ for $12 \mathrm{~h}$, and MP was extracted as previously published by Xiong (1993) with minor modifications (Chin et al., 2009a). In brief, $200 \mathrm{~g}$ of minced meat was washed three times with $800 \mathrm{~mL}$ of $0.1 \mathrm{M} \mathrm{NaCl}, 50 \mathrm{mM}$ sodium phosphate buffer ( $\mathrm{pH}$ 6.25), then the resulting myofibrillar solution was filtered using two sheets of cheesecloth and adjusted to $\mathrm{pH} 6.25$. Finally, the solution was washed with $1.6 \mathrm{~L}$ of $0.1 \mathrm{M}$ $\mathrm{NaCl}$ solution ( $\mathrm{pH}$ 6.25). Centrifugation was carried out at $3,000 \times \mathrm{g}$ for $15 \mathrm{~min}$ at $4^{\circ} \mathrm{C}$ using an auto-refrigerated centrifuge (J2-21, Beckman Inc, USA). After washing the muscle sample, the MP concentration of pellet was determined by the Biuret method (Gornall et al., 1949).

\section{Sample Preparation}

The MP solutions were formulated as shown in Table 1. In this study, the TG system consisted of TG and sodium caseinate $(\mathrm{SC})$ at a ratio of $6: 5(\mathrm{w} / \mathrm{w})$, and the CA system with $\mathrm{SA}$, calcium carbonate $(\mathrm{CC})$ and glucono- $\delta$-lactone $(\mathrm{GdL})$ at 1:0.3:1 (w/w), since these ratios were found as the best combination according to our preliminary study (Hong and Chin, 2009). The concentrations of each system indicated those of main components, e.g., $0.5 \mathrm{wt} \%$ CA system consisted of $0.5 \mathrm{wt} \% \mathrm{SA}, 0.15 \mathrm{wt} \% \mathrm{CC}$ and $0.5 \mathrm{wt} \% \mathrm{GdL}$. All ingredients were individually dissolved in $50 \mathrm{mM}$ sodium phosphate buffer ( $\mathrm{pH}$ 6.25) containing targeted salt concentrations from 0.1 to $0.4 \mathrm{M}$. TG, CC and GdL solutions were prepared just prior to mixing all ingredients. The MP solutions were centrifuged at $750 \times \mathrm{g}$ for $30 \mathrm{~s}$ at $4^{\circ} \mathrm{C}$ to remove air cells. For analysis, $5 \mathrm{~g}$ aliquots of samples were loaded into glass tubes with 12 $\mathrm{mm}$ diameter, and incubated at $4^{\circ} \mathrm{C}$ for $24 \mathrm{~h}$.

\section{pH}

The $\mathrm{pH}$ of the MP gels incubated at $4^{\circ} \mathrm{C}$ for $24 \mathrm{~h}$ was measured using a pH meter (MP 120, Mettler-Toledo $\mathrm{GmbH}$, Küsnacht, Switzerland) by inserting an electrode into the gels.

\section{Protein Fractionation}

Proteins were fractionated by the method of FernándezMartín et al. (2002). Five grams of MP gel stored at $4^{\circ} \mathrm{C}$ for $24 \mathrm{~h}$ was homogenized using a homogenizer (SMT Co. Ltd., Tokyo, Japan) at $2^{\circ} \mathrm{C}$ for $1 \mathrm{~min}$ with $20 \mathrm{~mL}$ of a $0.6 \mathrm{M} \mathrm{NaCl}$ solution, then centrifuged at $10,000 \times \mathrm{g}$ for 30 
Table 1. Experimental design and responses from seven dependent variables

\begin{tabular}{|c|c|c|c|c|c|c|c|c|c|c|}
\hline \multirow{3}{*}{ Treatments } & \multicolumn{3}{|c|}{ Independent variables } & \multicolumn{7}{|c|}{ Dependent variables $(n=9)$} \\
\hline & Salt (M) & TG system (wt $\%)$ & CA system $(w t \%)^{b}$ & \multirow{2}{*}{$\mathrm{pH}$} & \multicolumn{3}{|c|}{ Protein solubility (\%) } & \multicolumn{2}{|c|}{ Gel strength (g) } & \multirow{2}{*}{ Yield (\%) } \\
\hline & $\mathrm{X}_{1}$ & $\mathrm{X}_{2}$ & $\mathrm{X}_{3}$ & & S1 & S2 & S3 & Cold-set & Heated & \\
\hline 1 & $0.25(0)$ & $0.60(0)$ & $0.60(0)$ & 5.46 & 25.36 & 30.55 & 44.10 & 63.2 & 69.0 & 97 \\
\hline 2 & $0.25(0)$ & $0.60(0)$ & $0.00(-1.4)$ & 6.24 & 9.21 & 48.40 & 42.39 & 14.3 & 33.4 & 78 \\
\hline 3 & $0.25(0)$ & $0.60(0)$ & $0.60(0)$ & 5.46 & 26.30 & 32.73 & 40.96 & 65.3 & 70.1 & 99 \\
\hline 4 & $0.25(0)$ & $1.20(1.4)$ & $0.60(0)$ & 5.45 & 20.70 & 21.96 & 57.34 & 113.7 & 151.9 & 100 \\
\hline 5 & $0.40(1.4)$ & $0.60(0)$ & $0.60(0)$ & 5.45 & 14.25 & 28.94 & 56.81 & 118.2 & 208.9 & 100 \\
\hline 6 & $0.36(1)$ & $1.02(1)$ & $0.18(-1)$ & 5.98 & 9.37 & 25.11 & 65.52 & 253.3 & 310.2 & 96 \\
\hline 7 & $0.14(-1)$ & $1.02(1)$ & $1.02(1)$ & 5.33 & 18.36 & 30.48 & 51.16 & 494.8 & 307.5 & 93 \\
\hline 8 & $0.36(1)$ & $0.18(-1)$ & $1.02(1)$ & 5.22 & 28.00 & 44.82 & 27.18 & 110.6 & 134.4 & 98 \\
\hline 9 & $0.25(0)$ & $0.60(0)$ & $0.60(0)$ & 5.49 & 22.70 & 33.24 & 44.06 & 66.9 & 67.1 & 98 \\
\hline 10 & $0.25(0)$ & $0.60(0)$ & $1.20(1.4)$ & 5.25 & 18.46 & 45.41 & 36.13 & 280.9 & 161.6 & 96 \\
\hline 11 & $0.14(-1)$ & $0.18(-1)$ & $1.02(1)$ & 5.32 & 25.87 & 57.06 & 17.07 & 497.4 & 279.6 & 93 \\
\hline 12 & $0.25(0)$ & $0.60(0)$ & $0.60(0)$ & 5.50 & 29.94 & 30.91 & 39.15 & 65.5 & 71.8 & 99 \\
\hline 13 & $0.10(-1.4)$ & $0.60(0)$ & $0.60(0)$ & 5.53 & 22.10 & 37.29 & 40.60 & 252.2 & 130.5 & 89 \\
\hline 14 & $0.36(1)$ & $1.02(1)$ & 1.02 (1) & 5.29 & 23.45 & 25.39 & 51.16 & 174.3 & 205.8 & 100 \\
\hline 15 & $0.18(-1)$ & $0.18(-1)$ & $0.18(-1)$ & 5.97 & 8.73 & 60.30 & 30.97 & 6.5 & 20.6 & 88 \\
\hline 16 & $0.25(0)$ & $0.60(0)$ & $0.60(0)$ & 5.54 & 24.57 & 33.59 & 41.84 & 63.2 & 68.5 & 97 \\
\hline 17 & $0.25(0)$ & $0.00(-1.4)$ & $0.60(0)$ & 5.43 & 44.44 & 40.92 & 14.64 & 39.7 & 29.2 & 98 \\
\hline 18 & $0.25(0)$ & $0.60(0)$ & $0.60(0)$ & 5.53 & 27.50 & 32.70 & 39.80 & 64.3 & 69.8 & 98 \\
\hline 19 & $0.18(-1)$ & $1.02(1)$ & $0.18(-1)$ & 5.92 & 15.90 & 33.19 & 50.91 & 15.5 & 35.8 & 82 \\
\hline 20 & $0.36(1)$ & $0.18(-1)$ & $0.18(-1)$ & 5.96 & 12.88 & 59.46 & 27.67 & 25.6 & 177.6 & 100 \\
\hline
\end{tabular}

${ }^{a}$ The value presents transglutaminase (TG) concentration among TG system consisted with TG and sodium caseinate as a ratio of 6:5.

${ }^{\mathrm{b}}$ The value presents sodium alginate (SA) concentration among calcium alginate (CA) system consisted of SA, calcium carbonate and glucono- $\delta$-lactone as a ratio of 1:0.3:1.

$\min$ at $4^{\circ} \mathrm{C}$. This procedure was repeated once, and the two supernatants were mixed and expressed as S1 (saltsoluble) fraction. The remaining precipitate was homogenized at $2^{\circ} \mathrm{C}$ for $1 \mathrm{~min}$ with $20 \mathrm{~mL}$ of $4 \mathrm{M}$ urea buffer containing $0.3 \mathrm{M} \mathrm{NaCl}$, stored at $4^{\circ} \mathrm{C}$ for $24 \mathrm{~h}$, and then centrifuged twice with the same condition as before (S1). The combination of the two supernatants was expressed as S2 (urea-soluble) fraction. Protein concentrations (\%) of S1 and S2 fractions were determined by the Biuret method (Gornall et al., 1949). The insoluble fraction (S3) was numerically calculated by difference in percentages of total (100\%) and soluble fraction (sum of S1 and S2). According to Kauzmann (1959), S1 fraction is composed of proteins remaining in a native-like conformation and intermolecularly associated by electrostatic bonds, S2 is aggregated intermolecularly linked by hydrophobic interactions and hydrogen bonds, and $\mathrm{S} 3$ is protein aggregates formed by covalent, disulfide bonds and other insoluble proteins (Fernández-Martín et al., 2002).

\section{Gel Strength}

Gel strengths of cold-set MP gels after incubation at $4^{\circ} \mathrm{C}$ for $24 \mathrm{~h}$ were determined using an Instron universal testing machine (3340, Instron Corporation, Canton, MA, USA) equipped with a $9 \mathrm{~mm}$ diameter stainless steel plunger and cross-head speed $50 \mathrm{~mm} / \mathrm{min}$. The plunger was penetrated $1 \mathrm{~cm}$ into the MP gel of which dimensions were $12 \mathrm{~mm}$ diameter and $20 \mathrm{~mm}$ height. Maximum forces $(\mathrm{g})$ were taken and estimated as gel strengths of cold-set MP gels.

To evaluate the changes in gel strengths of cold-set MP gels after thermal treatment, the gels were heated from 0 to $75^{\circ} \mathrm{C}$ at $3^{\circ} \mathrm{C} / \mathrm{min}$ using a programmable water bath. After thermal treatment, samples were immediately cooled in an ice for $10 \mathrm{~min}$ and tempered in ambient for $4 \mathrm{~h}$. The measurement was performed with the same method as the cold-set gels.

\section{Cooking Yield}

The cooking yields were measured to evaluate the water binding properties of MP gels. The samples were thermal treated as described in previous section, and the liquid exudates were discarded. Cooking yields were determined by assessing the weight of gels, and expressed as a percentage of initial weight. 


\section{Statistical Analysis}

Response surface methodology was adapted to determine relationships between $\mathrm{NaCl}$ concentrations and MP gelling systems. Five levels of $\mathrm{NaCl}$, TG system and $\mathrm{CA}$ system concentrations were selected based on central composite design (Table 1). The complete design composed of 20 groups with six replications of the center point to estimate pure error (Cochran and Cox, 1992). The models were expressed by a second-order polynomial equations as:

$$
Y=\beta_{0}+\sum_{i}^{k} \beta_{i} X_{i}+\sum_{i}^{k} \beta_{i i} X_{i}^{2}+\sum_{i<j}^{k} \beta_{i j} X_{i} X_{j}
$$

where $Y$ is the estimated response, $\beta_{0}, \beta_{\mathrm{i}}, \beta_{\mathrm{ii}}$ and $\beta_{\mathrm{ij}}$ are regression coefficients, $X_{\mathrm{i}}$ and $X_{\mathrm{j}}$ are the independent variables, and $\mathrm{k}$ is the number of independent variables. The significances of all terms in the polynomial were judged using SAS 9.1 (SAS Institute, Inc., Cary, NC) by computing the F-value at a probability (p) of $0.001,0.01$ or 0.05 as described by Lee et al. (2006).

\section{Results and Discussion}

\section{pH}

The $\mathrm{pH}$ values of MP gels ranged from 5.4 to 6.2 , and inversely proportional to $\mathrm{CA}$ level regardless of salt or TG concentrations (data were not shown). In the regression model (Table 2), only the CA system affected the $\mathrm{pH}$ of MP gels, having both linear and quadratic terms $(p<0.001)$. Salt had an interaction effect with the CA system $(p<0.05)$, while the TG system had no effects on the $\mathrm{pH}$ of MP gels $(p>0.05)$. It is generally recognized that the activation of both CA and TG systems depends on the pH (Sakamoto et al., 1994; Mancini et al., 1999). For the CA system, GdL has the potential to slowly reduce the pH via acid hydrolysis (Ngapo et al., 1996), which results in the slow release of $\mathrm{Ca}^{2+}$ from CC (Draget et al., 1991). Although $\mathrm{CC}$ increased the $\mathrm{pH}$ with increasing incubation time, the degree of increment in $\mathrm{pH}$ was negligible when compared to the effect from GdL (Hong and Chin, 2009a). On the other hand, the initial pH of all components was adjusted to 6.25 , resulting in no effects of salt or the TG system on the final $\mathrm{pH}$ of MP gels.

\section{Protein Fractionation}

Increasing TG system tended to decrease the salt-soluble (S1) fraction of MP, while, the S1 fraction increased with increasing CA system up to $0.7 \%$ following decreased (Fig. 1). The CA system affected the S1 fraction, being

Table 2. Regression coefficients and analysis of variances of regression models

\begin{tabular}{|c|c|c|c|c|c|c|c|}
\hline \multirow{2}{*}{ Term } & \multirow{2}{*}{$\mathrm{pH}$} & \multicolumn{3}{|c|}{ Protein solubility } & \multicolumn{2}{|c|}{ Gel strength } & \multirow{2}{*}{ Yield } \\
\hline & & $\mathrm{S} 1$ & $\mathrm{~S} 2$ & S3 & Cold-set & Hot-set & \\
\hline$\beta_{0}$ & 6.28 & -8.7 & 81.2 & 28.3 & 170.2 & 131.3 & 68.8 \\
\hline \multicolumn{8}{|l|}{ Linear } \\
\hline$\beta_{1}$ & -0.42 & $168.0 *$ & -54.1 & -120.0 & $-2483.6 * * *$ & $-1839.8 * * *$ & $102.3 *$ \\
\hline$\beta_{2}$ & -0.03 & -11.4 & $-38.0^{*}$ & $49.9 * *$ & -151 & $-185.2 *$ & -17.9 \\
\hline$\beta_{3}$ & $-1.61 * * *$ & $53.3 * *$ & $-59.4 * * *$ & 3.3 & $667.0 * * *$ & $402.6 * * *$ & $44.2 * * *$ \\
\hline \multicolumn{8}{|l|}{ Quadratic } \\
\hline$\beta_{11}$ & 0.68 & $-351.3^{*}$ & 79.2 & 287.6 & $6225.7 * * *$ & $5868.9 * * *$ & -84.4 \\
\hline$\beta_{22}$ & -0.08 & 13.8 & 4.3 & -17.3 & 87.7 & $147.0 *$ & 7.9 \\
\hline$\beta_{33}$ & $0.75 * * *$ & $-34.0 * * *$ & $43.3^{* * *}$ & -8.3 & $284.6^{* * *}$ & $166.3 * *$ & $-25.4 * * *$ \\
\hline \multicolumn{8}{|l|}{ Crossproduct } \\
\hline$\beta_{12}$ & 0.41 & -22.8 & -4.8 & 21.7 & $791.6 * *$ & $446.8 *$ & 11.1 \\
\hline$\beta_{13}$ & $-0.55^{*}$ & 28.1 & -18.8 & -3.3 & $-2678.6^{* * *}$ & $-1884.3 * * *$ & -38.9 \\
\hline$\beta_{23}$ & 0.07 & -11.8 & 11.8 & 0.2 & -121.8 & -33.7 & 7.6 \\
\hline $\mathrm{R}^{2}$ & 0.97 & 0.50 & 0.73 & 0.78 & 0.87 & 0.80 & 0.63 \\
\hline \multicolumn{8}{|l|}{ F-value } \\
\hline Lack-of-fit & 0.58 & 2.09 & 1.44 & 0.91 & 1.34 & 1.15 & 2.07 \\
\hline \multicolumn{8}{|l|}{ Factor analysis $^{\mathrm{a}}$} \\
\hline Salt & 2.43 & 1.59 & 1.44 & 2.33 & $48.10 * * *$ & $36.96 * * *$ & $10.25 * * *$ \\
\hline TG system & 1.48 & 1.93 & $18.1 * * *$ & $23.78 * * *$ & $7.26^{* * *}$ & $8.73 * * *$ & 1.17 \\
\hline CA system & $377.02 * * *$ & $7.36 * * *$ & $6.95 * * *$ & 1.2 & $72.23 * * *$ & $34.39 * * *$ & $12.02 * * *$ \\
\hline
\end{tabular}

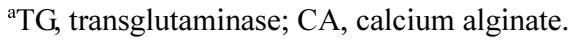

*Significant at 0.05 levels.

**Significant at 0.01 levels.

$* * *$ Significant at 0.001 levels. 

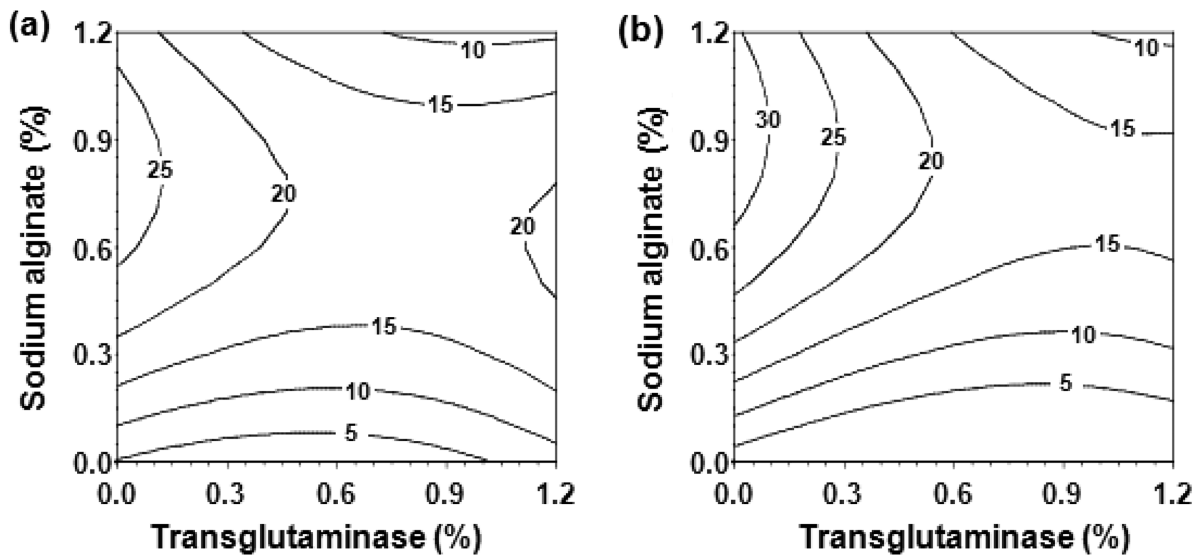

Fig. 1. Contour plots for salt-soluble fraction (S1) in myofibrillar proteins (MP) as a function of transglutaminase and sodium alginate at (a) $0.1 \mathrm{M}$ and (b) $0.4 \mathrm{M} \mathrm{NaCl}$ levels, respectively. The numbers on contour lines indicate the concentration of saltsoluble protein (\%) of MP.

linear $(p<0.01)$ and quadratic $(\mathrm{p}<0.001)$ terms. In the regression model, salt also had linear and quadratic effects $(p<0.05)$ on the $\mathrm{S} 1$ fraction, but no significance in factor analysis was found (Table 2). Meanwhile, the TG system had no influence on the S1 fraction which mainly consisted of proteins native-like or intermolecularly associated via electrostatic bonds (Fernández-Martín et al., 2002; Moreno et al., 2008). Not only was divalent $\mathrm{Ca}^{2+}$ much more effective at screening electrostatic repulsion and at binding to charged sites on MPs than monovalent $\mathrm{Na}^{+}$(Kulmyrzaev et al., 2000), but as $\mathrm{Ca}^{2+}$ simultaneously bound to two negatively charged surface on MPs (Bryant and McClements, 1998), the CA system might be more significant than salt in factor analysis. However, electrostatic interactions were very sensible to $\mathrm{pH}$, and SA was more sensible to $\mathrm{Ca}^{2+}$ than MPs. Furthermore, the bond strength of electrostatic interactions was not highly enough to form a MP gel (Park, 2000), so the impact of $\mathrm{Ca}^{2+}$ on electrostatic interactions in MPs was possibly lower than other interactions (S2 and S3 fractions).

The urea-soluble (S2) fraction, which mainly composed of aggregates intermolecularly linked by hydrophobic interactions and hydrogen bonds (Fernández-Martín et al., 2002; Moreno et al., 2008), was reversely proportional to TG system (Fig. 2). The CA system decreased the $\mathrm{S} 2$ fraction with increasing its concentration up to ca. $0.7 \%$. Both TG $(p<0.05)$ and CA $(p<0.001)$ systems had linear effects on the $\mathrm{S} 2$ fraction. In addition, the CA system affected this fraction by quadratic manner $(p<0.001)$. In factor analysis (Table 2), salt did not affect the S2 fraction $(p>0.05)$. Although neither hydrophobic interaction nor hydrogen bonds were sensitive to $\mathrm{pH}$ (Bryant and McClements, 1998), it seemed that there were involved some complicated factors in CA system. At low CA sys-
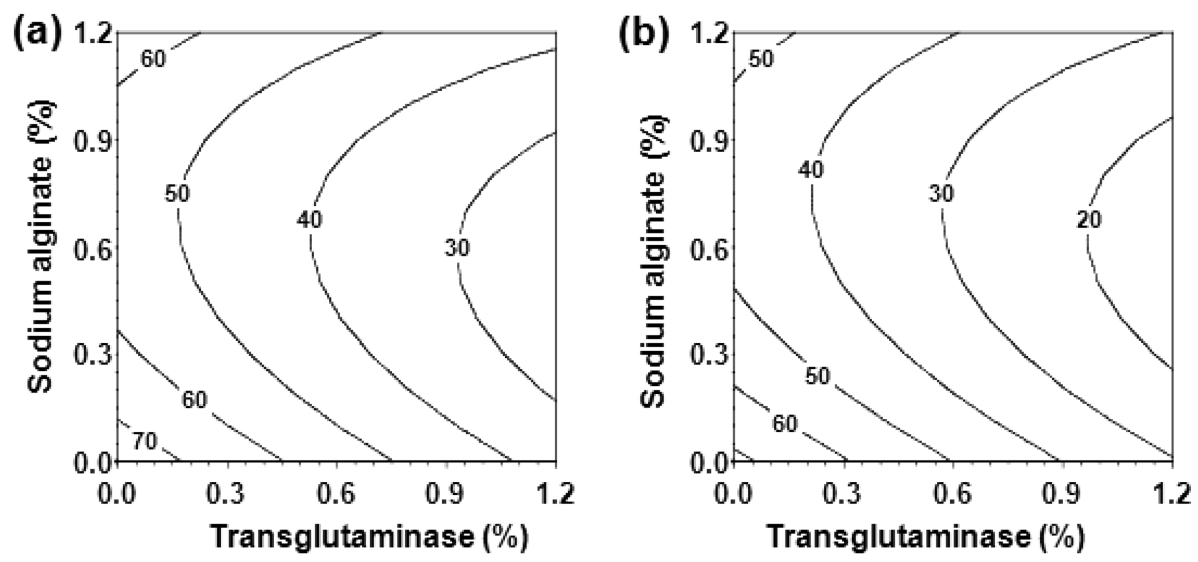

Fig. 2. Contour plots for urea-soluble fraction (S2) in myofibrillar proteins (MP) as a function of transglutaminase and sodium alginate at (a) $0.1 \mathrm{M}$ and (b) $0.4 \mathrm{M} \mathrm{NaCl}$ levels, respectively. The numbers on contour lines indicate the concentration of ureasoluble protein $(\%)$ of MP. 

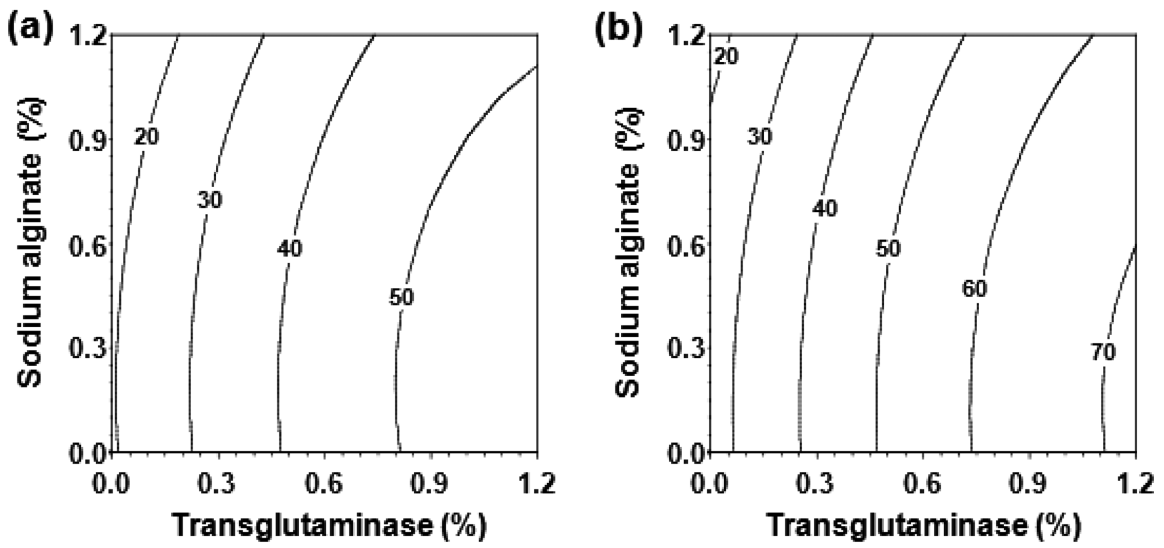

Fig. 3. Contour plots for insoluble fraction (S3) in myofibrillar proteins (MP) as a function of transglutaminase and sodium alginate at (a) $0.1 \mathrm{M}$ and (b) $0.4 \mathrm{M} \mathrm{NaCl}$ levels, respectively. The numbers on contour lines indicate the concentration of insoluble protein (\%) of MP.

tem, the liberated $\mathrm{Ca}^{2+}$ might break down the hydrogen bonds within MPs, resulting in lowered S2 fraction. Meanwhile, GdL induced acidification would be dominated at high amount of CA system, and thus increased the S2 fraction of MP. It should be noted that the CA system did not directly interact with MPs (Moreno et al., 2008; Hong and Chin, 2009a) and thermodynamical incompatibility may be present between MP and SA due to a negative net charge at 6.25 unit of initial $\mathrm{pH}$ (McClements, 2006). However, GdL induced an acidic condition which might have reduced the exclusive interactions between two biopolymers.

Fig. 3 shows the contour maps for the insoluble (S3) fraction as affected by MP gelling systems. Although the S3 fraction was increased at $0.4 \mathrm{M} \mathrm{NaCl}$, no effect of salt on the $\mathrm{S} 3$ fraction was observed both in regression and in factor analysis (Table 2). The CA system did not affect on the S3 fraction, while, the S3 fraction increased with increasing TG system. For both regression model and factor analysis, TG alone showed a linear effect $(p<0.01)$ on this fraction. Because TG caused cross-linking among MPs, the insoluble fraction, which was mainly covalent bonds (Fernández-Martín et al., 2002), was proportional to TG concentration. Moreover, the covalent bond had high bond strength among interactions (McClements, 1999), and therefore, had a direct correlation with gel strength.

\section{Gel Strength}

Gel strengths of cold-set MP incubated at $4^{\circ} \mathrm{C}$ for $24 \mathrm{~h}$ as affected by MP gelling systems are presented in Fig. 4 . At $0.1 \mathrm{M} \mathrm{NaCl}$, the gel strength was directly proportional to only CA system, while, the impact of TG system increased with increasing $\mathrm{NaCl}$ concentration, especially
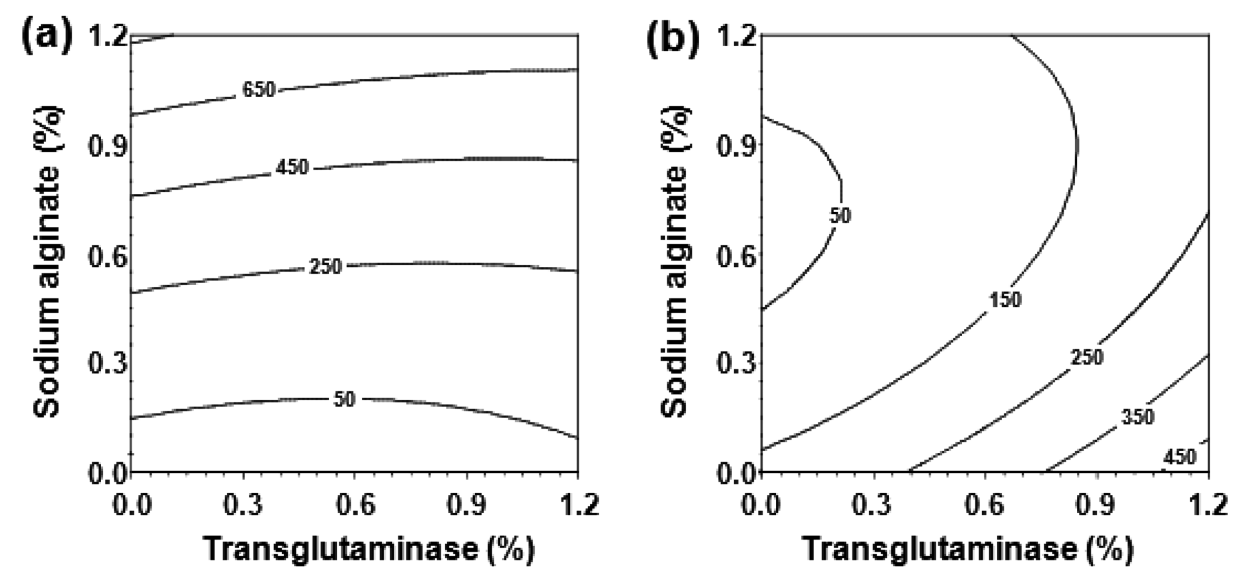

Fig. 4. Contour plots for cold-set gel strengths of myofibrillar proteins (MP) as a function of transglutaminase and sodium alginate at (a) $0.1 \mathrm{M}$ and (b) $0.4 \mathrm{M} \mathrm{NaCl}$ levels, respectively. The numbers on contour lines indicate the gel strength (g) of MP, and the optimized domain was colored $(>50 \mathrm{~g})$. 
at $0.4 \mathrm{M} \mathrm{NaCl}$. Both salt and the CA system influenced the gel strength of cold-set MPs $(p<0.001)$. Salt also had interaction effects with TG $(p<0.01)$ and CA $(p<0.001)$ systems. Meanwhile, the TG system alone had no effects on cold-set MP gel strength in a regression model $(p>$ 0.05 ). Since the TG system had no effects on gelation at $0.1 \mathrm{M} \mathrm{NaCl}$, gel strength was only proportional to CA system. This might be due to CA gel network formation at low $\mathrm{NaCl}$ concentration as well as acidification by GdL. Meanwhile, higher the SA concentration at $0.4 \mathrm{M}$ $\mathrm{NaCl}$ concentration, lower the gel strength, even though large amount of TG was added to the MP. The results indicated that CA gel lost their gelling characteristics at relatively high salt concentrations as well as inactivating the TG system and MP gel formation.

Since $50 \mathrm{~g}$ of gel strength was high enough to be eval- uated as a cold-set gel (Hong and Chin, 2009a), further increased gel strength $(>50 \mathrm{~g})$ of cold-set MP gels was not necessary for optimization. Meanwhile, the MP gel texture should not be disrupted after thermal treatment, and hence, gel strength of MP had to increase after thermal treatments. Therefore, a high MP gel strength after thermal treatment must be considered as an important gel characteristic, and the results are presented in Fig. 5. Contour maps for gel strength of MP after thermal treatment showed similar pattern with the cold-set gels, but the TG system had a remarkable effect on gel strength at high salt concentration. According to the regression model, all independent variables had linear and quadratic effects on MP gel strength after thermal treatment $(p<0.05)$ with the exception of the interaction between TG and CA systems (Table 2). The increased MP gel strength after thermal
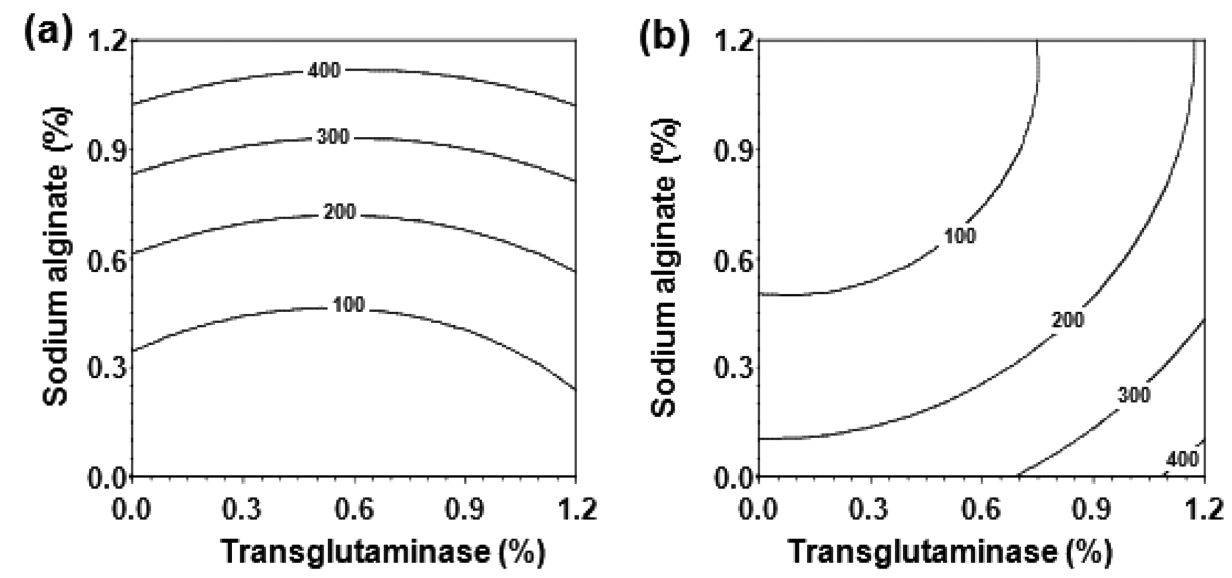

Fig. 5. Contour plots for gel strengths of heat treated myofibrillar proteins (MP) as a function of transglutaminase and sodium alginate at (a) $0.1 \mathrm{M}$ and (b) $0.4 \mathrm{M} \mathrm{NaCl}$ levels, respectively. The numbers on contour lines indicate the gel strength (g) of MP, and the optimized domain was colored $(>100 \mathrm{~g})$.
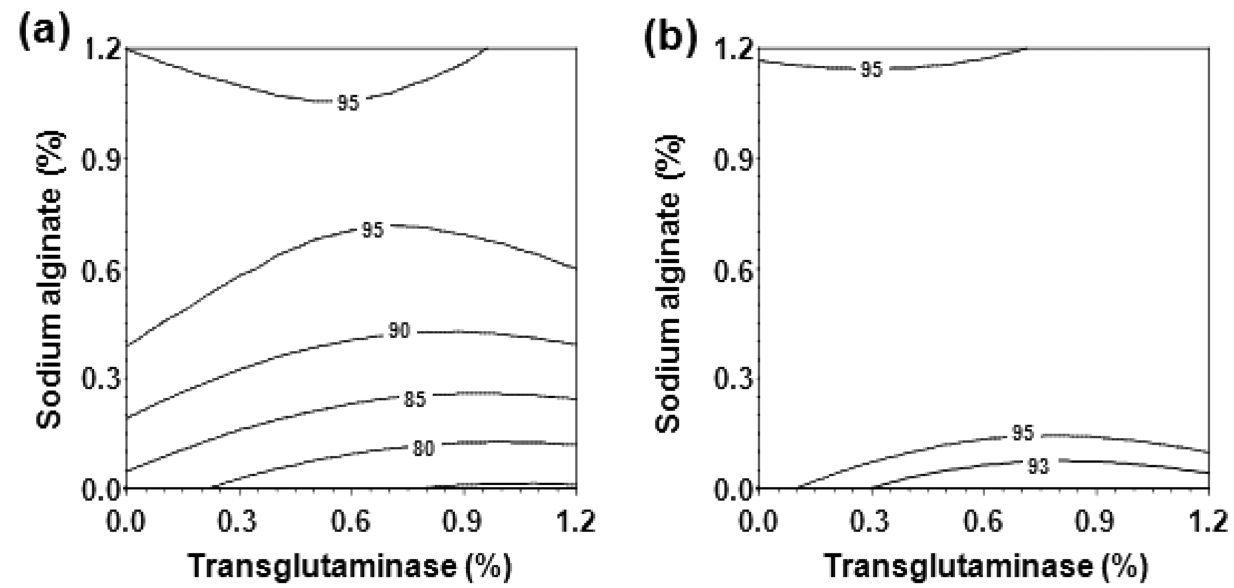

Fig. 6. Contour plots for cooking yield of myofibrillar proteins (MP) as a function of transglutaminase and sodium alginate at (a) $0.1 \mathrm{M}$ and (b) $0.4 \mathrm{M} \mathrm{NaCl}$ levels, respectively. The numbers on contour lines indicate the cooking yield (\%) of MP, and the optimized domain was colored (>95\%). 
processing was mainly due to the optimum activating condition for $\mathrm{TG}$ at $50^{\circ} \mathrm{C}$ and $\mathrm{pH} 9$ when $\mathrm{SC}$ was used as a substrate (Sakamoto et al., 1994). Consequently, the results showed that both TG and CA systems contributed to MP gel strength by balancing their efficacy under various salt concentrations and thermal treatment. The CA system governed gel strength of cold-set MP gels at low $\mathrm{NaCl}$ concentration, whereas MP gel strength after thermal treatment was attributed to $\mathrm{TG}$ at high $\mathrm{NaCl}$ concentration. In the two phase system composed of MPs and anionic polysaccharides, it would be useful to have a strategic approach such as in-situ gelation (Neiser et al., 1999), by which the phases of both MP and CA transformed from solution to viscoelastic gel without phase separation. At a moderate salt concentration as $0.25 \mathrm{M}$ $\mathrm{NaCl}$, a common concentration in muscle foods, viscoelastic gel could only be produced by combining the two systems. From the in-situ gelation point of view, the combination of the two systems had a potential benefit because MP gels had not only high gel strength at a coldset state, but also improved gel strength after thermal treatment with containing high amount of moisture.

\section{Cooking Yield}

Contour maps for the cooking yield of MP gels as a function of TG and SA levels are shown in Fig. 6. Increasing CA system improved the cooking yield of MP, while the cooking yield was decreased at extreme amount of CA system. Moreover, the cooking yield increased with increasing $\mathrm{NaCl}$ concentration. Salt concentrations had a positive effect on the yield of MP gels $(p<0.05)$. In addition, the CA system had linear and quadratic terms $(p<0.001)$ on the cooking yield of MP. However, no effect of the TG system on cooking yield was found $(p>0.05)$. According to our previous study (Hong and Chin, 2009a), the CA system improved the water holding capacity of cold-set MP gel after thermal treatment, but the addition of a high amount of GdL with a corresponding CA system concentration in this study showed negative effects on yields, mainly due to $\mathrm{pH}$ decline. On the other hand, no effect of TG system on yield of MP gel in this study was different from our previous finding, where TG system reduced the cooking yield of MP gel (Hong and Chin, 2010a). The TG system enhanced protein-protein interactions in MPs, hence it may result in high moisture loss during thermal processing (Chin et al., 2009a). However, increasing SC concentration with increasing TG in the current study might minimize the TG induced moisture loss in MP gel. In conclusion, the TG system contrib- uted to textural properties of MPs, particularly gel strength of MP after thermal treatment, while the CA system governed gel texture of cold-set state and water-binding property, and an acceptable viscoelastic MP gel with high moistness could only be formed by combining these two systems.

\section{Acknowledgements}

This study was supported by the Brain Korea 21 Project from the Ministry of Education and Human Resources Development, Republic of Korea.

\section{References}

1. Boles, J. A. and Shand P. J. (1998) Effect of comminution method and raw binder system in restructured beef. Meat $S c i$. 49, 297-307.

2. Bryant, C. M. and McClements, D. J. (1998) Molecular basis of protein functionality with special consideration of cold-set gels derived from heat-denatured whey. Trend Food Sci. Technol. 9, 143-151.

3. Chin, K. B., Go, M. Y., and Xiong, Y. L. (2009a) Konjac flour improved textural and water retention properties of transglutaminase-mediated, heat-induced porcine myofibrillar protein gel: Effect of salt level and transglutaminase incubation. Meat Sci. 81, 565-572.

4. Chin, K. B., Go, M. Y., and Xiong, Y. L. (2009b) Effect of soy protein substitution for sodium caseinate on the transglutaminase-induced cold and thermal gelation of myofibrillar protein. Food Res. Int. 42, 941-948.

5. Cochran, W. G. and Cox, G. M. (1992) Experimental designs, 2nd edn. John Wiley and Sons Inc., NY, pp 335-375.

6. Draget, K. I., Østgaard, K., and Smidsrød, O. (1991) Homogeneous alginate gels: A technical approach. Carbohydr. Polym. 14, 159-178.

7. Fernández-Martín, F., Cofrades, S., Carballo, J., and Jiménez-Colmenero, F. (2002) Salt and phosphate effects on the gelling process of pressure/heat treated pork batters. Meat Sci.61, 15-23.

8. Folk, J. E. (1980). Transglutaminase. Ann. Rev. Biochem. 49, 517-531.

9. Gornall, A. G., Bardawill, C. Y., and David, M. M. (1949) Determination of serum proteins by means of the biuret reaction. J. Biol. Chem. 177, 751-766.

10. Hong, G. P. and Chin, K. B. (2009) Optimisations of calcium alginate and microbial transglutaminase systems to form a cold-set myofibrillar protein gelation. Korean J. Food Sci. Ani. Resour. 5, 590-598.

11. Hong, G. P. and Chin, K. B. (2010a) Effects of microbial transglutaminase and sodium alginate on cold-set gelation of porcine myofibrillar protein with various salt levels. Food Hydrocolloid. 24, 444-451.

12. Hong, G. P. and Chin, K. B. (2010b) Evaluation of sodium 
alginate and glucono- $\delta$-lactone levels on the cold-set gelation of porcine myofibrillar protein at different salt concentrations. Meat Sci. 85, 201-209.

13. Kulmyrzaev, A., Chanamai, R., and McClements, D. J. (2000) Influence of $\mathrm{pH}$ and $\mathrm{CaCl}_{2}$ on the stability of dilute whey protein stabilized emulsions. Food Res. Int. 33, 15-20.

14. Kuraish, C., Sakamoto, J., Yamazaki, K., Susa, Y., Kuhara, C., and Soeda, T. (1997) Production of restructured meat using microbial transglutaminase without salt or cooking. $J$. Food Sci. 62, 488-490, 515.

15. Kütemeyer, C., Froeck, M., Werlein, H. D., and Watkinson, B. M. (2005) The influence of salts and temperature on enzymatic activity of microbial transglutaminase. Food Control. 16, 735-737.

16. Lee, W. C., Yusof, S., Hamid, N. S. A., and Baharin, B. S. (2006) Optimizing conditions for enzymatic clarification of banana juice using response surface methodology (RSM). $J$. Food Eng. 73, 55-63.

17. Mancini, M., Moresi, M., and Rancini, R. (1999) Mechanical properties of alginate gels: empirical characterization. $J$. Food Eng. 39, 369-378

18. McClements, D. J. (1999) Food emulsions: Principles, practice, and techniques. CRC Press, Boca Raton, pp. 17-37.

19. McClements, D. J. (2006) Non-covalent interactions between proteins and polysaccharides. Biotechnol. Adv. 24, 621-625.

20. Means, W. J. and Schmidt, G. R. (1986) Algin/calcium gel as a raw and cooked binder in structured beef steaks. J. Food Sci. 51, 60-65.

21. Means, W. J. and Schmidt, G. R. (1987) Restructuring fresh meat without the use of salt or phosphate. In: Advanced in meat research. Pearson, A. M. and Dutson, T. R. (eds.) Van Nostrand Reinhold, NY, Vol. 3, pp. 469-487.
22. Moreno, H. M., Carballo, J., and Borderías, A. J. (2008) Influence of alginate and microbial transglutaminase as binding ingredients on restructured fish muscle processed at low temperature. J. Sci. Food Agric. 88, 1529-1536.

23. Neiser, S., Draget, K. I., and Smidsrød, O. (1999) Interactions in bovine serum albumin-calcium alginate gel systems. Food Hydrocolloid. 13, 445-458.

24. Ngapo, T. M., Wilkinson, B. H. P., and Chong, R. (1996) 1,5Glucono-ä-lactone-induced gelation of myofibrillar protein at chilled temperature. Meat Sci. 42, 3-13.

25. Nielsen, G. S., Petersen, B. R., and Møller, A. J. (1995) Impact of salt, phosphate and temperature on the effects of a transglutaminase (F XIIIa) on the texture of restructured meat. Meat Sci. 41, 293-99.

26. Park, J. W. (2000) Ingredient technology and formulation development. In: Surimi and surimi seafood. Park, J. W. (ed.) Marcel Dekker Inc., NY, pp. 343-391.

27. Ramírez, J., Uresti, R., Téllez, S., and Vázquez, M. (2002) Using salt and microbial transglutaminase as binding agents in restructured fish products resembling hams. J. Food Sci. 67, 1778-1784.

28. Ramírez-Suárez, J. C. and Xiong, Y. L. (2003) Effect of transglutaminase-induced cross-linking on gelation of myofibrillar/soy protein mixtures. Meat Sci. 65, 899-907.

29. Sakamoto, H., Kumazawa, Y., and Motoki, M. (1994) Strength of protein gels prepared with microbial transglutaminase as related to reaction conditions. J. Food Sci. 59, 866-871.

30. Xiong, Y. L. (1993) A comparison of the rheological characteristics of different fractions of chicken myofibrillar proteins. J. Food Biochem. 16, 217-227.

(Received 2010.7.5/Revised 2010.9.21/Accepted 2010.9.29) 